\title{
Refractory Malignant Central Nervous System Neoplasm
}

National Cancer Institute

\section{Source}

National Cancer Institute. Refractory Malignant Central Nervous System Neoplasm. NCI

Thesaurus. Code C153842.

A malignant central nervous system neoplasm that is resistant to treatment. 